\title{
COMPETÊNCIA EM INFORMAÇÃO E NECESSIDADES DE INFORMAÇÃO DE IDOSOS: O PAPEL DO PROFISSIONAL DA INFORMAÇÃO NESSE CONTEXTO
}

\author{
INFORMATION LITERACY AND INFORMATION NEEDS \\ OF ELDERLY PEOPLE: THE ROLE OF THE \\ INFORMATION PROFESSIONAL IN THIS CONTEXT
}

\author{
Djuli Machado De Luccaa \\ Elizete Vieira Vitorinob
}

\begin{abstract}
RESUMO
Introdução: A situação do idoso no ambiente da sociedade da informação pode designar condição de vulnerabilidade social em alguns aspectos. A competência em informação, enquanto conjunto de habilidades, conhecimentos, atitudes e valores relacionados com a informação, pode configurar-se como um instrumento de transformação da realidade social do idoso. Essa pesquisa trata da competência em informação do idoso especificamente sob o foco das necessidades de informação, e insere o profissional da informação como mediador desse processo. Objetivos: descrever as características relacionadas à competência em informação e às necessidades de informação em idosos. A partir dessas descrições, estabelece algumas ações relacionadas à mediação da informação, que podem ser desenvolvidas pelo profissional da informação na ocasião de desenvolver a competência em informação do idoso. Metodologia: Trata-se de uma pesquisa bibliográfica, cujos dados foram coletados nas bases de dados Library and Information Science Abstracts (LISA), Web of Science e Scopus. Resultados: as necessidades de informação são subjetivas, e dependem da situação social, cultural ou política dos idosos. De toda forma, tais necessidades são relacionadas à saúde, finanças e lazer são recorrentes nos estudos analisados. Dentre as ações que podem ser desenvolvidas pelo profissional da informação que atua como mediador, estão iniciativas de socialização que preconizam a aquisição de informação acidental e estratégias de condensação de informação, que respeitam a condição cognitiva do idoso. Conclusão: preconiza que a competência em informação, para o idoso, pode representar um método de libertação da situação de opressão e vulnerabilidade no ambiente da sociedade da informação.
\end{abstract}

\footnotetext{
a Professora do Departamento de Ciência da Informação da Universidade Federal de Rondônia (UNIR). Doutoranda em Ciência da Informação do Programa de Pós-Graduação em Ciência da Informação da Universidade Federal de Santa Catarina (UFSC). E-mail: djuli.mdl@gmail.com

b Professora do Programa de Pós-Graduação em Ciência da Informação da Universidade Federal de Santa Catarina (UFSC). E-mail: elizete.vitorino@ufsc.br
} 
Descritores: Competência em Informação. Idosos. Profissional da informação. Mediação da informação. Vulnerabilidade informacional.

\section{INTRODUÇÃO}

No alvorecer do século XXI, o debate público sobre o desenvolvimento, seja em nível local ou global, permeia os campos da sociedade da informação e do conhecimento, e da influência dessa era nos diversos domínios sociais (WERTHEIN, 2000). Trata-se de um paradigma que reconhece, na informação, um elemento fundamental para o desenvolvimento econômico, social e cultural. O desafio social dessa ordem se constitui em "oferecer dignidade aos trabalhadores em serviços - a maioria da população mesmo nos países mais adiantados - que carecem de educação necessária para serem trabalhadores do conhecimento" (ROCHA, 2000, p. 42).

Como forma de consecução do desafio, temos observado uma diversidade de estudos na área da ciência da informação $(\mathrm{Cl})$ que contemplam o desenvolvimento da competência em informação dos indivíduos: acredita-se, então, que o movimento da competência em informação vem a responder às demandas da sociedade da informação. Muitos desses estudos ${ }^{1}$, inclusive, inserem bibliotecas e profissionais da informação como agentes responsáveis pelo êxito na missão de formar os "trabalhadores do conhecimento", conforme aponta levantamento realizado por Leite et al. (2016).

Uma evidência quanto ao reconhecimento do profissional da informação como agente promotor da competência em informação está revelada na pesquisa de Leite et al. (2016): os autores analisaram publicações que abordam a temática da competência em informação, e os resultados apontam que as abordagens de pesquisa que incluem a biblioteconomia, as bibliotecas e os

\footnotetext{
${ }^{1} \mathrm{O}$ trabalho de Campello (2003), por exemplo, ressalta que a biblioteca é o ambiente potencial para o estímulo da competência em informação, e insere o bibliotecário enquanto figura central no discurso do movimento. Dudziak (2003), por sua vez, afirma que a competência em informação é "o principal propósito de bibliotecas e bibliotecários".
} 
profissionais dessa área estão presentes na maior parte das pesquisas ${ }^{2}$ desse âmbito, especificamente naquele periódico analisado.

Por outro lado, essa mesma pesquisa revela uma concepção pouco humanista de tal movimento: a investigação salientou que, dentre as categorias com menor recorrência de pesquisas, incluem-se as abordagens envolvendo inclusão social e cidadania (LEITE et al., 2016, p. 161). Nesse sentido, é oportuna a condução de pesquisas que compreendam grupos vulneráveis, que são aqueles grupos que, por algum motivo, estão predispostos a ter a cidadania comprometida. A intenção, nesse caso, não é formar trabalhadores do conhecimento, mas sim indivíduos livres para determinar o curso da sua própria história. Para aqueles em condição de exclusão e/ou vulnerabilidade, o desenvolvimento da competência em informação pode representar um instrumento de empoderamento pessoal, autonomia, qualidade de vida e felicidade (AMERICAN LIBRARY ASSOCIATION, 1989).

Considerando o contexto apresentado, este trabalho se propõe a estudar um grupo que se encontra em situação de vulnerabilidade social. Compreende a população de idosos, que, ao contrário de outras camadas vulneráveis, como, por exemplo, a população de pobres e ignorantes, que tem diminuído em termos demográficos (UNESCO, 2015), representa um grupo em ascensão. Atualmente, há um idoso para cada nove indivíduos no planeta. O grupo de idosos hoje, no mundo, é a faixa etária que mais cresce em termos proporcionais (ORGANIZAÇÃO MUNDIAL DA SAÚDE, 2010). Dessa forma, investigar o desenvolvimento da competência em informação nesse grupo representa uma estratégia de inclusão social.

De modo específico, essa investigação se propõe a descrever as características relacionadas à competência em informação e às necessidades de informação em idosos. Essas características foram encontradas na literatura científica, a partir de uma busca bibliográfica realizada nas bases de dados

\footnotetext{
2 Leite et al. (2016) analisou abordagens de pesquisas sobre competência em informação publicadas no ENANCIB entre os anos de 1994 e 2015 a partir da criação de nove categorias de análise. São elas: ambiente de trabalho; bibliotecas; cidadania e aprendizado ao longo da vida; contextos/abordagens teóricas; diferentes grupos/comunidades; gestão da informação; inclusão social e digital; mídia e tecnologias; políticas e estratégias.
} 
Library and Information Science Abstracts (LISA), Web of Science e Scopus. Foram considerados úteis para a pesquisa os artigos de periódicos científicos publicados entre os anos de 2002 e 2016 nos idiomas inglês, português e espanhol, que apresentam os termos "information needs" e "information literacy", em conjunto com "elderly", "seniors" ou "olders" no título, resumo ou palavraschave do documento. Foram selecionadas, para a construção da pesquisa, as publicações recuperadas na busca que apresentam características referentes à origem das necessidades informacionais desse grupo.

A partir dessas descrições referentes às necessidades informacionais de idosos, incorporamos o profissional da informação no contexto, estimulando a reflexão acerca de algumas estratégias possíveis de serem percorridas por esse profissional na ocasião de desenvolver a competência em informação do idoso. O foco, nesse sentido, é a mediação da informação, que se trata de um processo que estimula a autonomia do indivíduo na sua trajetória de busca e uso da informação.

\section{COMPETÊNCIA EM INFORMAÇÃO E NECESSIDADES INFORMACIONAIS: MECANISMOS DE REDUÇÃO DA VULNERABILIDADE SOCIAL DO IDOSO NA SOCIEDADE DA INFORMAÇÃO}

O movimento denominado sociedade da informação é caracterizado pela centralização da informação para o desenvolvimento. Nesse contexto, os "fenômenos, processos, atividades de informação são reconhecidos como um plano constitutivo das atividades e manifestações econômicas, sociais e culturais" (GONZÁLEZ DE GÓMEZ, 2002, p. 30). Dessa forma, a sociedade da informação exerce influência em setores distintos, como a economia, a cultura e a estrutura social.

No aspecto social, uma expectativa levantada no surgimento da sociedade da informação diz respeito à universalização do conhecimento, que seria capaz de contribuir para a integração mundial dos povos, por meio da promoção de acesso universal tanto à infraestrutura quanto aos serviços de informação (WERTHEIN, 2000). 
De fato, o fenômeno da globalização, associado ao advento da internet, contribuiu para a universalização do conhecimento, pelo menos no aspecto que tange ao acesso à informação. O planeta transfigurou-se para aquilo que McLuhan denomina aldeia global, caracterizada como uma grande pátria onde as nações são interdependentes, e, por meio da troca de informações, compartilham aspectos culturais, econômicos e políticos. Além da universalização do conhecimento, a globalização também possibilitou a universalização do capital: nas atuais conjunturas, este é volátil, sem pátria, globalizado (DEMO, 2000). Esse pano de fundo capitalista descortinado tanto no espaço da sociedade da informação quanto no fenômeno da globalização revelou, dessa forma, não só uma sociedade da informação, mas também uma economia da informação (DEMO, 2000), redirecionando os fluxos de informação para os interesses do capital.

Na centralização dos fluxos de informação a serviço do capital, a busca pelo lucro e pelo desenvolvimento inovativo revelam-se como projetos centrais, e, enquanto isso, desconsidera-se o papel da informação na busca por valores sociais e na construção social da realidade (MAGNANI; PINHEIRO, 2011). Assim, os planos de desenvolvimento social prospectados na eclosão sociedade da informação desarraigam-se.

A economia da informação, além de desnutrir prospectos humanistas, também encerra um caráter excludente, revelado pelo movimento denominado capitalismo informacional. Este é caracterizado pela participação da informação no processo de valorização do capital, na medida em que os trabalhos informacionais são atribuídos de valor, e consumidos pelos indivíduos (DANTAS, 2012). O fundamento para a produção, que no capitalismo industrial constituía as máquinas e as matérias-primas, está, nesse modelo, concentrado no trabalho intelectual (EGLER, 2002). Assim, o caráter perverso do capitalismo informacional revela-se na ocasião que o ser humano é caracterizado pela sua capacidade de produzir: aqueles que não produzem, não fazem parte do círculo social produtivo.

Castells (2003, p. 219) afirma que essa nova configuração social "rejeita aqueles segmentos da sociedade e aqueles lugares de pouco interesse do ponto 
de vista da criação de valor." Dantas (2012), em seus estudos sobre Mosco (1988) e Schaff (1993), acredita que há, agora, uma divisão da humanidade: em cima, consolida-se uma minoria tecnologizada, com capacidade de produção e desfrute, que, em sua maioria, desenvolve atividades rentáveis para o sistema. Embaixo, constitui-se uma massa populacional desqualificada para produzir de acordo com os modelos do capital-informação: são denominados "desnecessários" (DANTAS, 2012 apud MOSCO; 1988; SCHAFF, 1993).

Os "desnecessários" são considerados oprimidos na ocasião em que possuem predisposição à violência, isto é, podem sofrer imposição de valores ou vontades por parte de um grupo social dominante (BAYLÃO, 2001). Esses grupos, ainda, são objeto de preconceito e discriminação por parte dos grupos opressores (BAYLÃO, 2001). Por essa razão, são predispostos a sofrer exclusão social, na medida em que são privados da participação da vida social pela característica distinta, que, para o grupo de desnecessários, é a incapacidade de produzir em termos econômicos.

O grupo de desnecessários, pela condição de predisposição à exclusão social provocada pelo capitalismo informacional, está em condição de vulnerabilidade social: tem acesso, participação e/ou oportunidade dificultada ou até mesmo vetada, a bens e serviços disponíveis para a população.

Cunha e Garrafa (2016) constatam que vulnerabilidade é um substantivo derivado do latim vulnus e que significa "ferida" e que o adjetivo vulnerável é usado para descrever o indivíduo que está suscetível ao ataque físico ou emocional, ou a danos. Para os autores, a vulnerabilidade é uma capacidade que pode ser descrita relacionando-a com o princípio da autonomia e que, dado o seu estado dependente e sua capacidade frequentemente comprometida, os grupos vulneráveis devem ser protegidos contra o risco, porque eles são alvo fácil de manipulação, como um resultado da sua condição. A figura 1 apresenta a tipologia dos grupos vulneráveis segundo uma parcela dos autores investigados para os fins deste trabalho. 


\section{Figura 1 - Tipologia dos grupos vulneráveis}

sem-teto, imigrantes, nômades, refugiados ou pessoas deslocadas, minorias raciais, prisioneiros, povos indígenas, crianças membros de comunidades sem conhecimento (MACKLIN, 2004)

\section{Grupos}

vulneráveis

membros subordinados de grupos hierárquicos como militares ou estudantes pessoas com diagnóstico de doenças mentais, pessoas idosas e/ou com demência e residentes em asilos, pobres, desempregados, ou em desvantagem econômica, pacientes em salas de emergência

Fonte: dados obtidos na pesquisa, adaptados de Sveinsdóttir e Rehnsfeldt (2005); Adger (2006); Fawcett (2009); Brombacher (2011); Gallacher (2013).

Quanto à figura 1, cabem algumas considerações. Segundo Beckett (2006 apud FAWCETT, 2009, p. 476-477), todos os indivíduos são vulneráveis em alguma fase ou situação da vida. Isto significa que, em vez de o conceito de vulnerabilidade utilizado referir-se a um grupo distinto com necessidades particulares, todos nós somos vulneráveis em algum aspecto e a maioria dos indivíduos é potencialmente vulnerável em relação a uma vasta gama de fatores de risco, bem como em novas formas de exclusão social.

Em se tratando do idoso, e, para Gallacher (2013), a vulnerabilidade se refere ao sentimento de que os seis sentidos: segurança, continuidade, sentimento de pertencimento, finalidade, realização e significado não estão sendo atendidos, o que, para a autora, com o grupo de idosos, torna-se uma tarefa complexa, ou um modo particular de ser para atender a tais necessidades e compreender seus sentimentos e os valores que são únicos.

No ambiente da sociedade da informação a aposentadoria pode denotar vulnerabilidade do idoso. Esta é uma condição alcançada por grande parte desses indivíduos (FECHINE; TROMPIERI, 2012), e a situação que provoca o desfavorecimento diz respeito ao fato de que o idoso aposentado está, normalmente, improdutivo em termos econômicos.

Outra característica que torna o idoso "desnecessário" na economia da informação diz respeito ao declínio da capacidade cognitiva. Este pode 
apresentar dificuldades na execução de trabalhos intelectuais, que exijam alto desempenho cognitivo. Sua vulnerabilidade nesse contexto é evidenciada na ocasião em que a medida de produção do sistema é a capacidade intelectual (DANTAS, 2012), que, para o idoso, pode estar comprometida por razões de decadência da cognição.

Nesta condição do idoso na sociedade da informação, a competência em informação assume caráter de libertação. Esta se refere ao conjunto de habilidades, atitudes, valores e conhecimentos (CAMPELLO, 2003) que o indivíduo desenvolve para utilizar os recursos e fontes de informação de forma consciente, criativa e benéfica (VITORINO; PIANTOLA, 2009).

Nos estudos científicos do campo da $\mathrm{Cl}$, é comum a concepção de que o desenvolvimento da competência em informação contribui para o desenvolvimento social: alguns estudos ressaltam o potencial de prover a autonomia, a liberdade, o empoderamento e independência (DUDZIAK, 2003; IFLA, 2005); e, ainda, outros estudos atentam para a possibilidade de esta competência possibilitar o alcance da qualidade de vida, da cidadania e da felicidade (AMERICAN LIBRARY ASSOCIATION, 1989; JOHNSTON; WEBBER, 2005).

Acreditamos que a competência em informação assume um caráter libertador na medida em o indivíduo competente em informação, a partir do empoderamento pessoal, toma consciência da situação de opressão e age para a transformação objetiva da realidade opressora (FREIRE, 2016, p. 70). Aquele que é competente em informação assume uma postura crítica e tem interferência no processo de transformação do mundo e da sua história.

Concebemos a competência em informação como um ciclo, que envolve a identificação de necessidades de informação, busca, avaliação e uso da informação. Embora possa ser estimulado em conjunto e mediado por terceiros, trata-se de um processo singular ao ser manifestado de forma diferente em cada um. O fluxograma da competência em informação, adaptado da pesquisa desenvolvida por Reis, Carvalho e Muniz (2011), está exposto na Figura 2 e apresenta as etapas desse processo. 


\section{Figura 2 - Fluxograma da Competência em Informação}

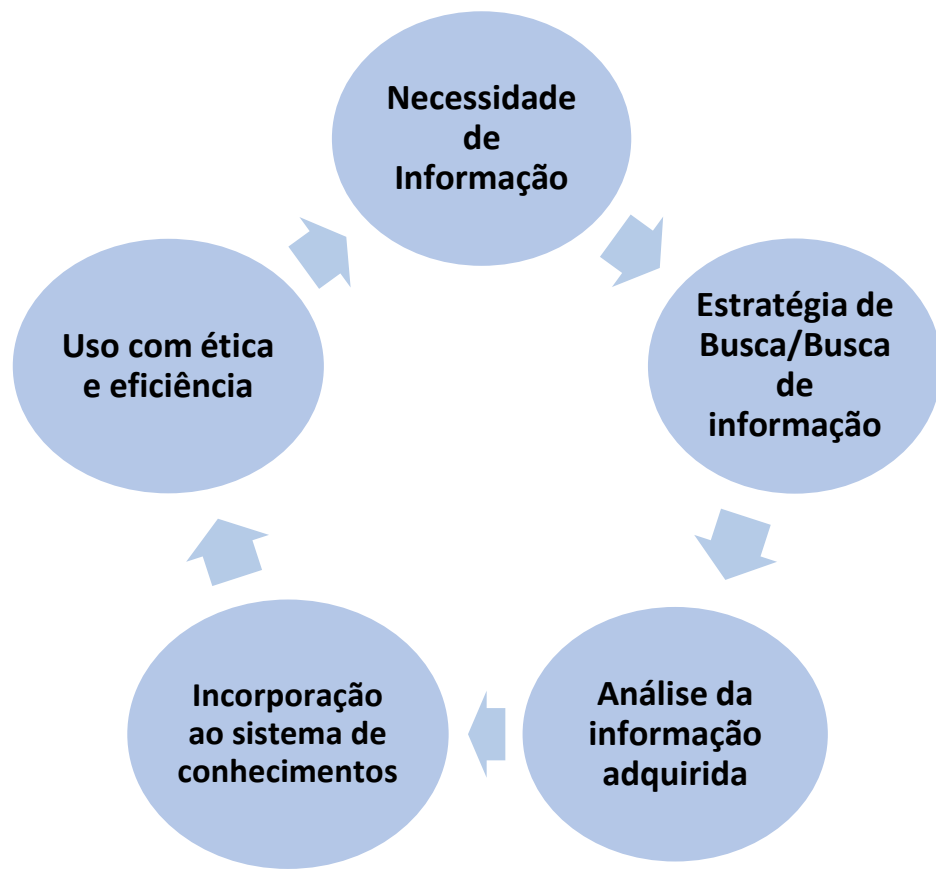

Fonte: Adaptado de Reis, Carvalho e Muniz (2011).

Dentre as etapas do ciclo apresentado na Figura 2, observamos que 0 reconhecimento de necessidades de informação é a chave para o desenvolvimento da competência em informação. Essa etapa representa a transformação de uma lacuna de conhecimento em uma demanda de informação. Miranda (2006), por sua vez, expressa que a lacuna de conhecimento é uma orientação para a ação: trata-se um processo de decisão, que delineia um problema e orienta a conduta. Identificar uma necessidade de informação é, dessa forma, conectar a situação à ação, e requer a proatividade própria da competência em informação para a mobilização de estratégias para atender à necessidade.

A necessidade de informação é concebida por Miranda (2006) como um estado de conhecimento insuficiente ou inadequado, identificado por um indivíduo quando este se confronta com a exigência de falta de informação necessária para prosseguir um trabalho. Trata-se, então, de uma necessidade derivada, comandada pela realização de uma necessidade fundamental. A informação, nesse sentido, é "o meio de desencadear uma ação com objetivo; é a condição necessária à eficácia dessa ação" (LE COADIC, 1996, p. 42). 
Martínez-Silveira e Oddone (2007) afirmam que as necessidades de informação geralmente se originam de situações pertinentes às atividades cotidianas da vida. Miranda (2006), por sua vez, esclarece que essas necessidades têm sua gênese nos papéis dos indivíduos na vida social. Ao considerarmos que essas situações são singulares, entendemos que as necessidades de informação estão em observância ao contexto individual de cada um.

Assim, competência em informação e necessidades de informação são processos subjetivos que se manifestam de maneira singular, impossibilitando a criação de padrões, modelos ou grandes esquemas objetivos. Podemos traçar alguns fundamentos quanto à origem nas necessidades de informação e ao desenvolvimento dessa competência em grupos semelhantes - e fazemos! porém, essas investigações estão pautadas na consciência de que o ser humano possui a característica de ser "complexo, contraditório, inacabado e, em permanente transformação" (MINAYO, 2010, p. 22).

Embora reconheçamos que competência em informação e necessidades de informação sejam movimentos subjetivos e singulares, é possível traçar algumas manifestações desses elementos que são comuns a certos grupos, como os idosos. Essas manifestações são essenciais para determinar condutas apropriadas ao profissional da informação ao estimular esse processo nos indivíduos, e estão elencadas na seção 3.

\section{A POPULAÇÃO DE IDOSOS: MAPEANDO SUAS CARACTERÍSTICAS E SUAS NECESSIDADES DE INFORMAÇÃO ${ }^{3}$}

O grupo de idosos é formado por aqueles indivíduos que cursam o período da velhice, e vivenciam os resultados do processo de envelhecimento, processo

3 A abordagem dessa pesquisa se dá a partir da literatura científica publicada predominantemente na área da ciência da informação e, dessa forma, a discussão acerca das características inerentes ao envelhecimento e ao idoso são direcionadas para pontos que interferem no desenvolvimento da competência em informação e na identificação das necessidades informacionais. O olhar para o idoso, nessa pesquisa, se dá a partir do campo da ciência da informação, que se trata de uma área interdisciplinar, que não investiga propriedades próprias aos aspectos do envelhecimento dos indivíduos, comuns às Ciências da Saúde, à Psicologia, entre outras. 
esse que é natural, involuntário e multidimensional.

A velhice é um conceito complexo em termos fisiológico, psicológico e social. Mascaro (2004, p. 89) define envelhecimento como "um processo heterogêneo e individualizado, que depende da interação entre fatores biológicos, sociais, psicológicos, econômicos, ambientais, históricos e culturais".

É por essa razão que o parâmetro para indicar a chegada a esse período pode divergir. Em alguns países menos desenvolvidos - e, em função da baixa expectativa de vida - podemos considerar como idoso aquele que possui 50 anos ou mais. Em outras nações, a terceira idade começa aos 65 anos. No Brasil, idoso é aquele que possui 60 anos ou acima disso, de acordo com o Estatuto do Idoso (BRASIL, 2003).

Existem algumas características que são comuns aos idosos, na maioria das vezes. A pesquisa desenvolvida por Charchat-Fichman et al. (2005), por exemplo, apresenta uma característica que é frequentemente citada na literatura: o declínio da cognição. Segundo os autores, no grupo de idosos, observa-se declínio da capacidade cognitiva, em função do próprio processo de envelhecimento ou em virtude do surgimento de síndromes demenciais, recorrentes nesta fase da vida. Por conta dessa ocorrência, esse período pode dificultar a assimilação de conteúdos e de informação (CHARCHAT-FISHMAN et al., 2005).

Existem, ainda, outros declínios que são comuns na fase da velhice. Williamson e Asla (2009) afirmam que há predisposição a problemas de saúde, que é inerente ao processo biológico de envelhecimento. Ainda, os laços sociais podem tornar-se tênues, em função da morte de amigos e entes queridos, ou também por conta da perda de mobilidade (WILLIAMSON; ASLA, 2009). A aposentadoria, que é comum para os idosos, também pode vir acompanhada da diminuição da renda: o indivíduo, dessa forma, passa a dispor de menos recursos financeiros para desfrutar de lazer e qualidade de vida. A aposentadoria ainda marca o início de um período potencialmente improdutivo em termos econômicos, e, ao passar a representar um ônus para a sociedade, o idoso pode considerar-se despido de papel social (FECHINE; TROMPIERI, 2012). 
De toda forma, a velhice também possui conveniências que podem ser experienciadas pelo idoso. Baptista (2006), em seus estudos sobre Erickson (1980; 1997) e Baltes (1998), afirma que a velhice é o período final do processo de construção do self do indivíduo, o período em que há o culminar da resolução positiva da crise final do ciclo de vida. Há, dessa forma, uma incorporação das memórias e experiências, e essas colaboram para que haja uma conexão entre passado e presente, de modo a criar uma imagem mítica de si mesmo. Nessa fase, o indivíduo passa a dispor de sabedoria. Trata-se, nesse sentido, de um período de profunda conexão com o self (BAPTISTA, 2006 apud ERICKSON, 1980; 1997; BALTES, 1998).

Além disso, a aposentadoria, apesar de poder vir acompanhada de diminuição de renda, possibilita ao idoso a conquista da estabilidade financeira. Há, também, maior tempo livre para atividades de lazer e de cuidados com a saúde, que são essenciais para o bem-estar e a qualidade de vida. A "perda de papel social" anteriormente relatada pode ser considerada benéfica: Doll et al. (2007), em seus estudos sobre a teoria sociológica do desengajamento, afirmam que a desvinculação do indivíduo com seu papel social - seja ele relacionado ao trabalho, amigos, família, entre outros - pode proporcionar aos idosos uma sensação de satisfação e contentamento, na medida em que estes passam a ser livres de responsabilidades perante o sistema social no qual estão vinculados.

De toda forma, essas conveniências estão condicionadas às circunstâncias daqueles que as vivenciam. Assim, o processo de envelhecimento além de multidimensional também é subjetivo - depende daquele que o experiencia - e a velhice bem-sucedida está atrelada a influências de ordem sociocultural, como, por exemplo, o "acesso a oportunidades educacionais, adoção de cuidados em saúde, e realização de ações que acompanham o curso da vida e se estendem às fases tardias da vida" (LIMA; SILVA; GALHARDONI, 2008, p. 796). A Figura 3 mostra elementos referentes aos declínios e às conveniências do envelhecimento. 
Figura 3 - Declínios e conveniências do envelhecimento

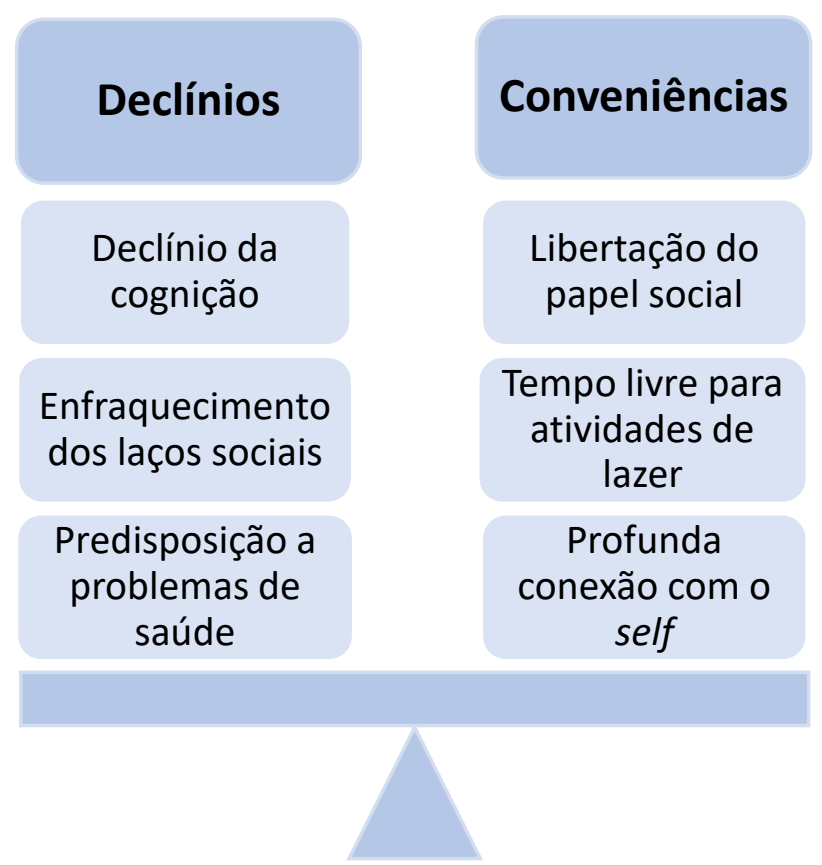

Fonte: dados obtidos na pesquisa, com base em Charchat-Fishman et al. (2005); Baptista (2006); Doll et al. (2007); Williamson e Asla (2009); Fechine e Trompieri (2012).

Seja de na forma de declínios ou de convivências, o envelhecimento é um processo de mudanças na vida do idoso, e as situações inerentes às mudanças provocam o aumento de ocorrências de necessidades de informação (EMMONS, 2004). Entretanto, as perdas fisiológicas e cognitivas dificultam a apreensão: os idosos, dessa forma, possuem percepção de que não possuem necessidades de informacionais, enquanto, na verdade, essas necessidades não são percebidas (WILLIAMSON, 1999).

Resultados obtidos por meio da pesquisa de Emmons (2004) constatam que as necessidades de informação mais recorrentes em idosos estão relacionadas à saúde, aos relacionamentos interpessoais e ao lazer. Williamson (1999) explorou a origem das necessidades informacionais dos idosos baseadas em seus próprios discursos, e constatou que há predominância de os déficits informacionais neste grupo estarem relacionados à saúde, finanças e lazer.

Porém, essas necessidades divergem ao observarmos as diferentes realidades: Emmons (2004) teve acesso a pesquisas relacionadas aos idosos de diferentes contextos sociais: de comunidades retiradas, imigrantes ou de grandes metrópoles. A autora constatou que, enquanto as necessidades 
informacionais de imigrantes estão relacionadas às notícias da pátria nativa, oportunidades educacionais para aprender o novo idioma e com relação às atividades de sua religião nativa, as necessidades informacionais dos idosos de uma metrópole estão predominantemente associadas a atividades de lazer, de assistência domiciliar de enfermagem e relações familiares. Assim, a origem das necessidades informacionais dos idosos está vinculada à situação social, política e cultural de cada grupo.

Algumas pesquisas deram conta de traçar algumas características de necessidades de informação que são comuns aos idosos que possuem atributos semelhantes. O Quadro 1 apresenta estudos que procuraram caracterizar a natureza das $\mathrm{NI}$ de idosos de diferentes grupos.

Podemos perceber, a partir do conjunto de dados disponíveis elencados no Quadro 1, que as necessidades de informação sobre saúde são recorrentes: estão contempladas nos estudos dos cinco autores citados. Quanto ao lazer e às finanças, estas são indicadas por três dos cinco autores. Ou seja, ao que tudo indica, independentemente da situação social, cultural ou política dos idosos, é na necessidade de informação sobre saúde que ocorre um ponto comum.

Portanto, há indicadores que nos mostram que o desenvolvimento desse conjunto de capacidades é benéfico ao idoso e, por conseguinte, pode ser promovido e estimulado por um profissional, no processo de mediação da informação. Nesse contexto, o profissional da informação apresenta papel primordial.

\section{Quadro 1 - Origem das necessidades de informação de idosos}

\begin{tabular}{|c|c|c|c|}
\hline Autoria & Contexto & Natureza das NI & Barreiras para acesso \\
\hline $\begin{array}{l}\text { Emmons } \\
(2004)\end{array}$ & $\begin{array}{l}\text { Revisão de literatura } \\
\text { sobre necessidades de } \\
\text { informação de idosos de } \\
\text { diferentes grupos }\end{array}$ & $\begin{array}{l}\text { Saúde, } \\
\text { relacionamentos } \\
\text { interpessoais, } \\
\text { finanças e lazer }\end{array}$ & $\begin{array}{l}\text { Dificuldades na } \\
\text { utilização do } \\
\text { computador }\end{array}$ \\
\hline $\begin{array}{l}\text { Mane; Paiva } \\
(2007)\end{array}$ & $\begin{array}{l}\text { Idosos participantes de } \\
\text { um Grupo da Terceira } \\
\text { Idade (GTI) }\end{array}$ & $\begin{array}{l}\text { Saúde, lazer, } \\
\text { educação, } \\
\text { segurança }\end{array}$ & $\begin{array}{l}\text { Barreiras financeiras } \\
\text { quanto ao acesso (a } \\
\text { aposentadoria não } \\
\text { corresponde às } \\
\text { necessidades do idoso, } \\
\text { impossibilitando que } \\
\text { este indivíduo busque } \\
\text { informação) }\end{array}$ \\
\hline
\end{tabular}




\begin{tabular}{|c|c|c|c|}
\hline $\begin{array}{l}\text { Williamson; } \\
\text { Asla (2009) }\end{array}$ & $\begin{array}{l}\text { Idosos situados na } \\
\text { quarta idade (período } \\
\text { não-cronológico da vida } \\
\text { em que o indivíduo } \\
\text { apresenta declínio da } \\
\text { saúde física, diminuição } \\
\text { da capacidade cognitiva } \\
\text { e tenuidade dos laços } \\
\text { sociais). }\end{array}$ & $\begin{array}{l}\text { saúde, finanças e } \\
\text { lazer }\end{array}$ & $\begin{array}{l}\text { Déficits físicos e } \\
\text { principalmente } \\
\text { cognitivos que } \\
\text { dificultam a apreensão } \\
\text { da informação }\end{array}$ \\
\hline $\begin{array}{l}\text { Giacalone et } \\
\text { al. (2009) }\end{array}$ & $\begin{array}{l}\text { Idosos que receberam } \\
\text { diagnóstico de câncer, } \\
\text { pacientes de um instituto } \\
\text { localizado no nordeste } \\
\text { da Itália }\end{array}$ & $\begin{array}{l}\text { Recuperação da } \\
\text { saúde, possíveis } \\
\text { consequências } \\
\text { da doença, } \\
\text { possíveis } \\
\text { tratamentos; } \\
\text { maneiras de lidar } \\
\text { com os efeitos } \\
\text { colaterais }\end{array}$ & $\begin{array}{l}\text { Problemas de } \\
\text { comunicação entre o } \\
\text { idoso e os profissionais } \\
\text { - tanto os oncologistas } \\
\text { quanto os cuidadores. }\end{array}$ \\
\hline $\begin{array}{l}\text { Edewor; } \\
\text { ljiekhuamhen; } \\
\text { Emeka-ukwu } \\
\text { (2016) }\end{array}$ & $\begin{array}{l}\text { Idosos nigerianos } \\
\text { residentes em uma área } \\
\text { governamental local }\end{array}$ & $\begin{array}{l}\text { Saúde, finanças, } \\
\text { decisões do dia- } \\
\text { a-dia, transporte, } \\
\text { notícias }\end{array}$ & $\begin{array}{l}\text { Falta de equidade na } \\
\text { oferta de conteúdo; } \\
\text { incapacidade por conta } \\
\text { de saúde ou outros } \\
\text { fatores pessoais }\end{array}$ \\
\hline
\end{tabular}

Fonte: Dados obtidos na pesquisa. Elaborado pelas autoras.

\section{O PAPEL DO PROFISSIONAL DA INFORMAÇÃO NO DESENVOLVIMENTO DA COMPETÊNCIA EM INFORMAÇÃO DE IDOSOS}

Concebemos a competência em informação como a capacidade desenvolvida pelo indivíduo de criar significados a partir de informações adquiridas (VARELLA, 2006, p. 20). Trata-se de um ato cognitivo e social, que, a partir da criação de sentidos, fornece condições para estabelecer consciência crítica para interferir na própria história. Dadas as características, reconhecemos o desenvolvimento da competência em informação como um processo de aprendizagem.

Varela (2006) salienta que o organismo funciona como o centro de uma complexa rede de interações, formada por fatores biogenéticos, culturais, experimentais e emocionais. Todo processo de apreensão de conteúdo deve transcorrer por essa rede, cujos pontos - que são relativos ao indivíduo e ao meio - estão diretamente interligados. O desenvolvimento da competência em informação, concebido como um processo de aprendizagem, emerge, então, da ação recíproca e interativa do sujeito com os objetos (meio) (VARELA, 2006). 
Além disso, Varella (2007, p. 124) destaca que a aprendizagem é uma "uma produção cultural, diretamente relacionada com a linguagem e com a interação social". Então, essa construção envolve, além do indivíduo e o objeto (meio), um segundo indivíduo: trata-se de "um movimento complexo, no qual os sujeitos interagem entre si, mas também com as informações, processando-as para, a partir de seus enquadramentos, de suas possibilidades cognitivas, se apropriarem dos conteúdos acessados" (GOMES, 2008, p. 1). Nesse sentido, reconhecemos que a competência em informação é resultado de um processo que envolve uma relação recíproca entre os seres humanos e a informação.

Esse processo de interação entre indivíduos - que é intrínseco a qualquer ato de apreensão de informação - pode se dar por meio da mediação da informação. Essa relação de mediação, estabelecida com um "indivíduo mais experiente", segundo Varella (2007, p. 23), promove zonas mais amplas de desenvolvimento crítico e criativo, que, a partir de processos complexos de raciocínio, promovem a autonomia do pensamento.

A mediação da informação, no contexto da competência em informação, pode ser exercida pelo profissional da informação. Essa atividade é caracterizada por Almeida Júnior (2008, p. 3) como uma "ação de interferência [...] direta ou indireta; consciente ou inconsciente; singular ou plural; individual ou coletiva; que propicia a apropriação de informação que satisfaça, plena ou parcialmente, uma necessidade informacional".

Para Belluzzo, Santos e Almeida Júnior (2014), a ação do profissional da informação, no contexto da competência em informação, ativa e potencializa a construção de conhecimentos, na medida em que o indivíduo mediado consegue, de certa forma, avaliar todo o contexto em que está inserido, para satisfazer suas necessidades informacionais. Dessa forma, esse ato modifica, altera e transforma os estímulos do mediado, "proporcionando-lhe uma postura ativa, crítica, reflexiva e independente frente à pesquisa de informações para a satisfação de necessidades informacionais" (BELLUZZO; SANTOS; ALMEIDA JÚNIOR, 2014, p. 68).

O papel do mediador - no ambiente da competência em informação ou em qualquer processo de aprendizagem - é de facilitador, incentivador ou 
motivador da aprendizagem: esse indivíduo se apresenta com a disposição de ser uma "ponte" entre o aprendiz e sua aprendizagem - não uma "ponte estática", mas uma "ponte rolante" (MASETTO, 2000). Dessa forma, sua responsabilidade consiste em auxiliar o aprendiz a "coletar informações, relacioná-las, organizálas, manipulá-las, discuti-las e debatê-las" (MASETTO, 2000, p. 145), para que seja possível produzir um conhecimento que seja significativo para o indivíduo que aprende, um conhecimento "que se incorpore ao seu mundo intelectual e vivencial, e que o ajude a compreender sua realidade humana e social, e mesmo a interferir nela (MASETTO, 2000, p. 145). O mediador, assim, conecta os extremos da "ponte", e facilita a comunicação da informação para os indivíduos que dela necessitam (FREIRE, 2010, p. 99).

No ambiente da competência em informação, manifestamos que a mediação é oportuna para a conquista de missões bem-sucedidas no conhecimento, pois "[...] o público em geral não é especialista em informação" (WOLTON; 2003). Atribuímos ao profissional da informação a responsabilidade de mediar o processo de competência em informação, e, nesse sentido, reconhecemos que esse profissional, assume, nessa questão, a responsabilidade de promover a competência em informação da comunidade em que participa (CAMPELLO, 2003; DUDZIAK, 2003).

Na perspectiva de oferecer alguns subsídios para práticas profissionais de mediação direcionadas ao grupo de idosos e, com vistas a traçar estratégias úteis para este fim por profissionais da informação, Williamson e Asla (2009), por exemplo, ressaltam que a solução pode se dar a partir da aquisição de "informação acidental", ou seja, informação adquirida involuntariamente, sem uma necessidade explícita: pode ser gerada na conversa informal com amigos, ou pelos meios de comunicação em massa, notadamente a televisão, jornal e rádio.

Pettigrew (1999) sugere ações que integrem informações acidentais, a partir do conceito de information grounds (bolsões de informação, para o português). $O$ autor acredita que podem ser criados bolsões de informação para grupos específicos, que se caracterizam por reuniões ou atividades em grupo organizadas para um propósito, mas que a intenção é o compartilhamento de 
informação dos mais diversos aspectos. A interação e troca de conhecimentos, nesse sentido, acontece naturalmente. Dessa forma, a promoção de esforços, a partir do profissional da informação, no sentido de possibilitar maior interação social e troca de experiências é essencial: seja na criação de grupos de convívio em bibliotecas, centros de informação e locais públicos, seja por meio da organização de encontros periódicos nestes locais. O que importa em um information ground é a interação social, e qualquer iniciativa que envolva a formação de redes sociais é válida.

Em acréscimo às possibilidades da mediação, Gust (2006) salienta que o profissional da informação deve estar consciente da diminuição das capacidades cognitiva e funcional dos idosos, e atender à proposta denominada por "keep it simple" (para o português, mantenha as coisas simples). Gust (2006) sugere que o profissional ofereça, no processo de mediação, o mínimo de conteúdo possível, e de uma forma simples. Para a autora, quanto mais conteúdo for oferecido, menor será a sua absorção (GUST, 2006).

Acreditamos, ainda, que outros profissionais também têm papel fundamental na promoção do movimento da competência em informação tanto para os idosos, quanto para a sociedade em geral. Concebemos a competência em informação como um processo transdisciplinar, que "permeia todo e qualquer processo de aprendizado, investigação, criação, resolução de problemas e tomada de decisão" (DUDZIAK, 2008, p. 42), e acreditamos ser oportuna a integração dos bibliotecários com profissionais da educação, assistentes sociais, psicólogos, profissionais da saúde, profissionais do turismo, advogados, entre outros. $\mathrm{O}$ trabalho colaborativo é fundamental para que o movimento cumpra a missão de colaborar para o processo de emancipação humana, de desenvolvimento socioeconômico e constituir-se como um fator de promoção da inclusão social (DUDZIAK, 2008).

\section{CONSIDERAÇÕES FINAIS}

Esse trabalho buscou apresentar um tópico de pesquisa pouco explorado nos estudos científicos no âmbito da competência em informação: a abordagem dessa competência enquanto instrumento com capacidade de promover a 
inclusão social (LEITE et al., 2016). Para dar conta desse propósito, apresentamos, com base na literatura, necessidades de informação de idosos pertencentes a camadas diversas da sociedade. A identificação das necessidades informacionais é útil para traçar estratégias para a promoção da competência em informação desse grupo em ambientes de informação, a partir do processo de mediação da informação. Esses caminhos podem estimular a autonomia, o empoderamento pessoal, a qualidade de vida e a liberdade desses idosos, e podem reduzir substancialmente a situação de vulnerabilidade.

Acreditamos que o profissional da informação exerce sua missão social ao atender as necessidades de informação de pessoas, grupos e comunidades em condição de vulnerabilidade, seja de ordem cognitiva, financeira, funcional, entre outros. O grupo de idosos apresenta essas e outras características da mesma ordem e, por isso, a mediação é essencial à competência em informação.

Ressaltamos que a integração entre profissionais é benéfica, e é somente a partir do trabalho mútuo entre profissionais de áreas distintas que podemos explorar, com profundidade, aspectos cognitivos, sociais, culturais e educacionais da competência em informação, assumindo, efetivamente, o caráter libertador do movimento.

Ainda: é pelo fato de que, para o idoso, as necessidades em informação serem "imprevisíveis" que o desenvolvimento da competência em informação se mostra essencial. Não podemos prever, com exatidão, tais necessidades, nem tampouco quando estas surgirão. Por isso, estimular o "ser consciente" pode se dar pelo viés da mediação e o "ser competente em informação" é consequência!

\section{REFERÊNCIAS}

ADGER, W. N. Vulnerability. Global Environmental Change, v. 16, n. 3, p. 268-281, ago. 2006. Disponível em:

http://dx.doi.org.ez46.periodicos.capes.gov.br/10.1016/j.gloenvcha.2006.02.006 Acesso em: 15 ago. 2018.

ALMEIDA JÚNIOR, O. F. Mediação da informação e múltiplas linguagens. In: Encontro Nacional de Pesquisa em Ciência da Informação, 9, 2008, São Paulo. Anais... São Paulo: ANCIB, 2008, p. 1-14. 
AMERICAN LIBRARY ASSOCIATION. Presidential Committee on Information Literacy: final report. Washington, 1989. Disponível em: http://www.ala.org/acr//publications/whitepapers/presidential. Acesso em: 15 ago. 2018.

BAPTISTA, N. J. A. Virtudes e desvantagens do envelhecimento à luz do texto proverbial português: cruzamentos da psicologia popular com a psicologia científica. 2006. 131 f. Dissertação (Mestrado em Psicopatologia e Psicologia clínica) - Instituto Superior em Psicologia Aplicada, Lisboa, 2006. Disponível em: http://repositorio.ispa.pt/handle/10400.12/339. Acesso em: 15 ago. 2018.

BAYLÃO, R. S. Um conceito operacional de minorias. Revista da Fundação Escola Superior do Ministério Público do Distrito Federal e Territórios, v. 17, n. 1, p. 209-233, jan./jun. 2001. Disponível em:http://www.escolamp.org.br/arquivos/17_09.pdf. Acesso em: 15 ago. 2018.

BELLUZZO, R. C. B.; SANTOS, C. A.; ALMEIDA JÚNIOR, O. F. A. A competência em informação e sua avaliação sob a ótica da mediação da informação: reflexões e aproximações teóricas. Informação \& Informação, Londrina, v. 19, n. 2, p. 60-77, maio/ago. 2014. Disponível em: http://www.uel.br/revistas/uel/index.php/informacao/article/view/19995/pdf_21. Acesso em: 15 ago. 2018.

BRASIL. Lei n. 10.741 , de $1^{\circ}$ de outubro de 2003. Dispõe sobre o Estatuto do Idoso e dá outras providências. Diário Oficial da União, Brasília, Seção 1, p. 1, 04 out. 2003.

BROMBACHER, A. Vulnerability. Quality and Reliability Engineering International, v. 27, n. 1, p. 1, fev. 2011. Disponível em: http://onlinelibrarywiley-com.ez46.periodicos.capes.gov.br/doi/10.1002/qre.1186/epdf. Acesso em: 15 ago. 2018.

CAMPELLO, B. O movimento da competência informacional: uma perspectiva para o letramento informacional. Ciência da Informação, Brasília, v. 32, n. 3 , p. 28-37, set./dez. 2003.

CASTELLS, M. A galáxia da Internet. Rio de Janeiro: Jorge Zahar, 2003.

CHARCHAT-FISHMAN, H.; CARAMELLI, P.; SAMESHIMA, K.; NITRINI, R. Declínio da capacidade cognitiva durante o envelhecimento. Revista Brasileira de Psiquiatria, São Paulo, v. 27, n. 12, p. 79-82, 2005.

CUNHA, T.; GARRAFA, V. Vulnerability: a key principle for global bioethics? Cambridge Quarterly of Healthcare Ethics, v. 25, n. 2, p. 197-208, 2016. Disponível em:

http://journalscambridgeorg.ez46.periodicos.capes.gov.br/action/displayAbstract ?fromPage $=$ online $\&$ aid $=10225159 \&$ fileld $=$ S096318011500050X. Acesso em: 15 ago. 2018. 
DANTAS, M. Trabalho com informação: valor, acumulação, apropriação nas redes do capital. Rio de Janeiro: Centro de Filosofia e Ciências Humanas da UFRJ, 2012. 248 p.

DEMO, P. Ambivalências da sociedade da informação. Ciência da Informação, Brasília, v. 29, n. 2, p. 37-42, maio/ago. 2000. Disponível em: http://www.scielo.br/pdf/\%0D/ci/v29n2/a05v29n2.pdf. Acesso em: 15 ago. 2018.

DOLL, J.; GOMES, A.; HOLLERWEGER, L.; PECOITS, R. M., ALMEIDA, S. T. de. Atividade, desengajamento, modernização: teorias sociológicas clássicas sobre o envelhecimento. Estudos Interdisciplinares sobre Envelhecimento, v. 12, n. 1, p. 7-33, 2007. Disponível em:

http://www.seer.ufrgs.br/RevEnvelhecer/article/viewFile/4977/2846. Acesso em: 15 ago. 2018.

DUDZIAK, E. A. Information Literacy: princípios, filosofia e prática. Ciência da Informação, Brasília, v. 32, n. 1, p. 23-35, jan./abr. 2003. Disponível em: http://revista.ibict.br/ciinf/article/view/1016. Acesso em: 15 ago. 2018.

DUDZIAK, E. A. Os faróis da sociedade da informação: uma análise crítica sobre a situação da competência em informação no Brasil. Informação e Sociedade: estudos, João Pessoa, v. 18, n. 2, p. 41-53, maio/ago. 2008. Disponível em:

http://www.periodicos.ufpb.br/ojs/index.php/ies/article/view/1704. Acesso em: 15 ago. 2018.

EDEWOR, N.; IJIEKHUAMHEN, O. P.; EMEKA-UKWU, U. P. Elderly people and their information needs. Philosophy and Practice (e-journal), paper $\mathrm{n}$. 1332, 2016. Disponível em: http://digitalcommons.unl.edu/libphilprac/1332. Acesso em: 15 ago. 2018.

EGLER, T. T. C. Exclusão e inclusão na sociedade do conhecimento. Cadernos IPPUR/UFRJ, v. 16, n. 1, s/p, jan./jul. 2002. Disponível em: http://www.espaco.ippur.ufrj.br/textos/Exclusao_\%20e_\%20inclusao_\%20socie d_do_conhecimento.pdf. Acesso em: 15 ago. 2018.

EMMONS, K. Review of literature: the information needs and informationseeking behavior of older adults. Drexel university information resources and technology, 2004. Disponível em: http://www.pages.drexel.edu/ kje26/. Acesso em: 15 ago. 2018.

FAWCETT, B. Vulnerability: questioning the certainties in social work and health. International Social Work, v. 52, n. 4, p. 473-484, jul. 2009. Disponível em: http://isw.sagepub.com/content/52/4/473.full.pdf+html. Acesso em: 15 ago. 2018.

FECHINE, B. R. A.; TROMPIERI, N. O processo de envelhecimento: as principais alterações que acontecem com o idoso com o passar dos anos. InterSciencePlace, Rio de Janeiro, v. 1, n. 20, p.106-132, jan./mar. 2012. 
FREIRE, I. M. A consciência possível para uma ética da informação na sociedade em rede. In: FREIRE, G. H. A. Ética da informação: conceitos, abordagens, aplicações. João Pessoa: Ideia, 2010.

FREIRE, P. Pedagogia do oprimido. 60. ed. São Paulo: Paz e Terra, 2016.

GALLACHER, R. Vulnerability... This practice profile is based on NS667 Abley C (2012): responding to vulnerability in old age: patient-centred care. Nursing Standard. v. 27, n. 45, p. 49, 2013.

GIACALONE, A.; TALAMINI, R.; FRATINO, L.; SIMONELLI, C.; BEARZ, A.; SPINA, M.; TIRELLI, U. Cancer in the elderly: the caregiver's perception of senior patients' informational needs. Archives of Gerontology and Geriatrics, v. 49, n. 2, p. 121-125, set./out. 2009. Disponível em:

https://www.sciencedirect.com/science/article/abs/pii/S0167494308002094. Acesso em: 27 nov. 2018.

GOMES, H. F. A mediação da informação, comunicação e educação na construção do conhecimento. DataGramaZero: Revista de Ciência da Informação, v. 9, n. 1, fev. 2008.

GONZÁLEZ DE GÓMEZ, M. N. Novos cenários políticos para a informação.

Ciência da Informação, Brasília, v. 31, n. 1, p. 27-40, jan./abr. 2002.

Disponível em: http://revista.ibict.br/ciinf/article/view/975. Acesso em: 15 ago. 2018.

GUST, K. Teaching with Tiffany's: A "go-lightly" approach to information literacy instruction for adult and senior learners. Reference services Review, v. 34, n. 4, p. 557-569, out./dez. 2006. Disponível em:

https://www.deepdyve.com//p/emerald-publishing/teaching-with-tiffany-s-a-golightly-approach-to-information-literacy-FkcnE289Zi. Acesso em: 15 ago. 2018.

INTERNATIONAL FEDERATION OF LIBRARIES ASSOCIATIONS AND INSTITUTIONS (IFLA). Declaração de Alexandria sobre competência Informacional e aprendizado ao longo da vida. In: National Fórum on Information Literacy, 2005. Disponível em:

www.ifla.org/lII/wsis/BeaconlnfSocpt.html. Acesso em: 21 jul. 2017.

JOHNSTON, B.; WEBBER, S. As we may think: Information literacy as a discipline for the information age. Reseach Strategies, s/l, v. 20, n. 1, p. 108121, 2005. Disponível em:

https://www.sciencedirect.com/science/article/pii/S0734331006000097. Acesso em: 15 ago. 2018.

LE COADIC, Y. A ciência da informação. Brasília: Briquet de Lemos, 1996.

LEITE, C.; SIMEÃO, E. L. M. S.; NUNES, E. M. de A.; FERES, F. C. B. G. G.; FERES, G. G.; FREIRE, I. M.; BELLUZZO, R. C. B. Cenário e perspectiva da produção científica sobre competência em informação (Colnfo) no Brasil: 
estudo da produção no âmbito da ANCIB. Informação e Sociedade: Estudos, v. 26, n. 3, p. 151-168, set./dez. 2016. Disponível em:

http://www.periodicos.ufpb.br/ojs2/index.php/ies/article/view/31983. Acesso em: 15 ago. 2018.

LIMA, A. M. M.; SILVA, H. S.; GALHARDONI, R. Envelhecimento bemsucedido: trajetórias de um constructo e novas fronteiras. Interface -

Comunicação, Saúde, Educação, v. 12, n. 27, p. 795-807, out./dez. 2008.

Disponível em: http://www.scielo.br/pdf/icse/v12n27/a10v1227.pdf. Acesso em: 15 ago. 2018.

MACKLIN, R. Bioética, vulnerabilidade e proteção. In: GARRAFA, V.; PESSINI L. (Org.). Bioética: poder e injustiça. São Paulo: Loyola, 2004. p. 59-70.

MANE, E. B.; PAIVA, E. B. Necessidades de informação de idosos: pesquisa com o grupo "alegria de viver", SESC-PB. Biblionline, João Pessoa, v. 3, n. 2, s/p, 2007. Disponível em:

http://periodicos.ufpb.br/index.php/biblio/article/view/1641/1685. Acesso em: 15 ago. 2018.

MAGNANI, M. C. B.; PINHEIRO, M. M. K. "Regime" e "Informação": a aproximação de dois conceitos e suas aplicações na ciência da informação.

Liinc em Revista, v. 7, n. 2, jul./dez. 2011. Disponível em:

http://revista.ibict.br/liinc/article/view/3278/2899. Acesso em: 15 ago. 2018.

MARTÍNEZ-SILVEIRA, M.; ODDONE, N. Necessidades e comportamento informacional: conceituação e modelos. Ciência da Informação, Brasília, v. 36, n. 2, maio/ago. 2007. Disponível em:

http://revista.ibict.br/ciinf/article/view/1182/1345. Acesso em: 15 ago. 2018.

MASCARO, S. A. O que é velhice. São Paulo: Brasiliense, 2004. (Coleção primeiros passos).

MASETTO, M. Mediação pedagógica e o uso da tecnologia. In: MORAN, J. M.; MASETTO, M.; BEHRENS, M. A. Novas tecnologias e mediação pedagógica. 5. ed. São Paulo: Papirus, 2000.

MINAYO, M. C. S. (Org.) Pesquisa Social: teoria, método e criatividade. 29. ed. Petrópolis: Vozes, 2010.

MIRANDA, S. V. Como as necessidades de informação podem se relacionar com as competências informacionais. Ciência da Informação, Brasília, v. 35, n.3, p. 99-114, set./dez. 2006. Disponível em:

http://www.scielo.br/pdf/ci/v35n3/v35n3a10.pdf. Acesso em: 15 ago. 2018.

ORGANIZAÇÃO MUNDIAL DA SAÚDE - WORLD HEALTH ORGANIZATION. Global health and aging. National Institute of Aging, U.S. Department of Health and Human Services, 2010. Disponível em: 
http://www.who.int/ageing/publications/global_health.pdf.Acesso em: 21 jul. 2017.

PETTIGREW, K. Waiting for chiropody: contextual results from an ethnographic study of the information behaviour among attendees at community clinics. Information Processing and Management, s/l, v. 35, n. 3, p. 801-817, nov./dez. 1999.

REIS, M. K. S.; CARVALHO, M. M.; MUNIZ, E. M. "Information Literacy" ou competência em informação como elemento promotor do desenvolvimento do capital intelectual. In: Congresso Brasileiro de Biblioteconomia e Documentação, 24, 2011, Maceió. Anais... Maceió: FEBAB, 2011.

ROCHA, M. P. C. A questão da cidadania na sociedade da informação. Ciência da Informação, v. 29, n. 1, jan./abr. 2000. Disponível em: http://revista.ibict.br/ciinf/article/view/897/934. Acesso em: 15 ago. 2018.

SVEINSDÓTTIR, H.; REHNSFELDT, A. Vulnerability. Scandinavian journal of caring sciences, v.19, n. 2, p. 85, 2005. Disponível em: http://dx.doi.org.ez46.periodicos.capes.gov.br/10.1111/j.14716712.2005.00329.x. Acesso em: 15 ago. 2018.

UNESCO. Relatório de Monitoramento Global de EPT - Educação para todos 2000-2015: progressos e desafios - relatório conciso Brasília: UNESCO, 2015. Setor de Educação da Representação da UNESCO no Brasil. Disponível em: http://unesdoc.unesco.org/images/0023/002325/232565por.pdf. Acesso em: 15 ago. 2018.

VARELA, A. V. A explosão informacional e a mediação na construção do conhecimento. In: MIRANDA, A.; SIMEÃO, E. Alfabetização digital e acesso ao conhecimento. Brasília: Universidade Federal de Brasília, 2006. Cap. 1, p. 15-32. (Comunicação da informação, v. 4).

VARELA, A. V. Informação e Autonomia: a mediação segundo Feuerstein. São Paulo: Editora Senac, 2007. 368 p.

VITORINO, E. V.; PIANTOLA; D. Competência Informacional - bases históricas e conceituais: construindo significados. Ciência da Informação, Brasília, v. 38, n. 3, p. 130-141, set/dez. 2009. Disponível em:

http://revista.ibict.br/ciinf/article/view/1236/1414. Acesso em: 15 ago. 2018.

WERTHEIN, J. A sociedade da informação e seus desafios. Ciência da informação, v. 29, n. 2, p. 71-77, 2000. Disponível em:

http://revista.ibict.br/ciinf/article/view/889/924. Acesso em: 15 ago. 2018.

WILLIAMSON, K. The role of research in professional practice: with reference to the assessment of the information and library needs of older people. Australasian Public Libraries and Information Services, s/l, v. 12, n. 4, 145-153, 1999. 
WILLIAMSON, K.; ASLA, T. Information behavior of people in the fourth age: Implications for the conceptualization of information literacy. Library and Information Science Research, s/l, v. 31, n. 2, p. 76-83, abr./jun. 2009.

WOLTON, D. Internet, e depois? Uma teoria crítica das novas mídias. Porto Alegre: Sulina, 2003.

\title{
INFORMATION LITERACY AND INFORMATION NEEDS OF ELDERLY PEOPLE: THE ROLE OF THE INFORMATION PROFESSIONAL IN THIS CONTEXT
}

\begin{abstract}
Introduction: Information Literacy is a set of skills, knowledge, attitudes and values related to information that represents a way to change social reality. This research deals with elderly's information literacy under the focus of information needs and inserts the information professional as mediator of this process in the elderly. Objective: to present characteristics of information literacy and information needs of the elderly. From these descriptions, this it establishes some actions related to information mediation which can be done by the information professional when promoting information literacy of elderly. Methodology: it is a bibliographic research, whose data was collected from databases Library and Information Science Abstracts (LISA), Web of Science and Scopus. Findings: information needs are subjective, and it depends on the social, cultural or political situation of the elderly. In any case, information needs related to health, finance and leisure are recurrent in the studies analyzed. Some actions that can be developed by the information professional who acts as mediator can include the formation of information grounds, that provides the acquisition of accidental information; and information condensation strategies, which respect the cognitive condition of the elderly. Conclusion: it advocates that information literacy for the elderly may represent a way to release the situation of oppression and vulnerability in the information society environment.
\end{abstract}

Descriptors: Information Literacy. Professional of Information. Elderly People. Information mediation.

\section{ALFABETIZACIÓN EN INFORMACIÓN Y NECESIDADES DE INFORMACIÓN DE ANCIANOS: EL PAPEL DEL PROFESIONAL DE LA INFORMACIÓN}

\begin{abstract}
RESUMEN
Introducción: alfabetización en información es un conjunto de habilidades, conocimientos, actitudes y valores relacionados con la información que representa una forma de transformar la realidad social de las personas mayores. Esta investigación se ocupa de la Alfabetización en información de los ancianos bajo el foco de las necesidades de información, e inserta al profesional de la información como mediador de este proceso en los ancianos. Objetivo: presentar las características de la Alfabetización en información y las necesidades de información de los ancianos. A partir
\end{abstract}


de estas descripciones, se establecen algunas acciones relacionadas con la mediación de la información que pueden ser desarrolladas por el profesional de la información al desarrollar la Alfabetización en información de los ancianos. Metodología: es una investigación bibliográfica, cuyos datos fueron recogidos en la literatura científica, de bases de datos Biblioteca y Ciencia de la Información Abstracts (LISA), Web of Science y Scopus. Resultados: las necesidades de información son subjetivas y dependen de la situación social, cultural o política de los ancianos. En cualquier caso, las necesidades de información relacionadas con la salud, las finanzas y el ocio son recurrentes en los estudios analizados. Algunas acciones que pueden ser desarrolladas por el profesional de la información que actúa como mediador pueden incluir la formación de información, que proporciona la adquisición de información accidental; $Y$ estrategias de condensación de información, que respetan la condición cognitiva de los ancianos. Conclusión: defiende que la alfabetización en información para los ancianos puede representar una forma de liberar la situación de opresión y vulnerabilidad en el entorno de la sociedad de la información.

Descriptores: Alfabetización en Información. Ancianos. Profesional de la información. Mediación de la información. 